\title{
Efeito do congelamento e da pré-incubação sobre o isolamento de estafilococos coagulase-negativo em amostras de leite de ovelhas
}

\section{Effect of freezing and preincubaton on isolation of coagulase- negative staphylococci from ewes' milk samples}

\author{
Maiara Garcia Blagitz ${ }^{*}$; Mariana Ricciardi²; Camila Freitas Batista ${ }^{3}$; Fernando \\ Nogueira de Souza ${ }^{4}$; Milton Ricardo Azedo ${ }^{5}$; Viviani Gomes ${ }^{6}$; Alice Maria Melville \\ Paiva Della Libera ${ }^{6}$
}

\begin{abstract}
Resumo
O objetivo do presente trabalho foi avaliar o efeito do congelamento e da incubação do leite de ovelhas da raça Santa Inês sobre os resultados da cultura bacteriológica. Desta forma, 45 amostras de leite ovino foram coletadas, e submetidas aos seguintes tratamentos: cultura bacteriológica (T1), e simultaneamente incubadas a $37^{\circ} \mathrm{C}$ por 18 horas (T2) e congeladas a $-20^{\circ} \mathrm{C}$ por 24 horas (T3). Após esses períodos, as amostras dos $\mathrm{T} 2$ e $\mathrm{T} 3$ foram submetidas à cultura bacteriológica. $\mathrm{O}$ T2 possibilitou aumento no isolamento de estafilococos coagulase-negativo (ECN) comparadas ao T1, não ocorrendo o mesmo com o T3. No entanto, o T2 permitiu o desenvolvimento de bactérias normalmente presentes na microbiota dos ductos dos tetos em ovelhas sadias, como o Bacillus spp. Os resultados do presente estudo indicam que a incubação pode ser aplicada para a detecção de ECN na tentativa de reduzir resultados falsonegativos na cultura bacteriológica do leite de ovelhas da raça Santa Inês, determinando o uso mais eficiente dos recursos laboratoriais e a redução dos custos para os proprietários.

Palavras-chave: Mastite. Ovelhas. Diagnóstico. Cultura. Estafilococos coagulase-negativo.
\end{abstract}

\begin{abstract}
Milk samples from 45 halves were collected from lactating ewes to evaluate the effect of freezing and incubation of the whole milk on the qualitative results of bacteriologic culture. Thus, these milk samples were submitted to the following treatments: standard culture technique (T1), incubation for $18 \mathrm{~h}$ at $37^{\circ} \mathrm{C}$ (T2) and thawing at $-20^{\circ} \mathrm{C}$ for $24 \mathrm{~h}$ (T3). After these periods, the milk samples from $\mathrm{T} 2$ and $\mathrm{T} 3$ were submitted to standard culture technique. The T2 showed an increase in the proportion of coagulasenegative staphylococci (CNS) recovery compared to T1, although the same cannot be predicted by T3. Conversely, the T2 allows the growth of some bacteria present in clinically healthy teats ducts as Bacillus spp.. The results of the present study indicated that the incubation of the whole milk can be applied to detection of CNS in ewes' milk in attempt to reduce the false-negative culture milk samples that can lead to a more efficient use of laboratory resources and reduce costs to herd owners.
\end{abstract}

Key words: Mastitis. Ewes. Diagnosis. Culture. Coagulase-negative staphylococci.

\footnotetext{
1 Médica Veterinária, Doutora pelo Departamento de Clínica Médica da Faculdade de Medicina Veterinária e Zootecnia, Universidade de São Paulo, FMVZ, USP. E-mail: magblagitz@usp.br

2 Médica Veterinária pela FMVZ, USP.E-mail: mari_ricciardi@yahoo.com.br

3 Médica Veterinária, Mestranda do Departamento de Clínica Médica da FMVZ, USP. E-mail: camila_vet69@yahoo.com.br

4 Médico Veterinário, Mestre pela FMVZ, USP. E-mail: nogueirasouza@usp.br

5 Médico Veterinário, Doutor pela FMVZ, USP. E-mail: mr.azedo@uol.com.br

${ }^{6}$ Prof $^{a}$ Dr $^{\mathrm{a}}$ do Departamento de Clínica Médica da FMVZ, USP. E.mail: dellalibera@usp.br; viv_vet@yahoo.com.br

* Autor para correspondência
} 
$\mathrm{Na}$ ovinocultura alguns fatores relacionados à sanidade são considerados como limitantes na sua exploração, entre os quais se destaca a mastite ovina. A ocorrência da mastite em ovelhas, além da redução da produção e da qualidade do leite, determina perdas econômicas devido a mortes, custos com tratamentos e gastos adicionais com mãode-obra, e redução de desempenho de cordeiros. Esse último aspecto ganha maior importância nos sistemas de produção brasileiros cuja população ovina crescente é predominantemente mantida em sistemas extensivos e semi-extensivos de criação (VERÍSSIMO et al., 2010).

Entre o grupo de microrganismos causadores de mastite em ovinos, destaca-se os estafilococos coagulase-negativo (ECN), considerados os principais patógenos causadores de infecções intramamárias (BERGONIER et al., 2003). Em bovinos, os ECN são considerados patógenos de menor importância e determinam discreto aumento da celularidade, características que não podem ser consideradas para ovinos (PENGOV, 2001). Neste contexto, Leitner et al. (2001) demonstraram significante aumento da celularidade por este grupo de patógenos, sugerindo menor resistência e/ou aumento da resposta imune frente a estes patógenos em ovinos. Ainda, a alta persistência das infecções por estes patógenos tem sido frequentemente descrita nestes animais (LEITNER et al., 2001; BERGONIER et al., 2003). Usualmente, as infecções são associadas a baixa susceptibilidade in vitro a antimicrobianos, uma vez que ECN podem desenvolver facilmente resistência a diferentes antimicrobianos (GONZALO et al., 2002; DELLA LIBERA et al., 2011).

Assim, o diagnóstico preciso é essencial para os programas de controle de mastites em ovinos, já que animais positivos podem ser tratados, separados do rebanho ou descartados. Além disso, a falha na identificação de animais infectados pode resultar em aumento na prevalência desta enfermidade, uma vez que animais falso-negativos podem funcionar como fonte de infecção no rebanho. A detecção definitiva da mastite é baseada no isolamento de patógenos de amostras de leite (ZECCONI et al., 1997; GODDEN et al., 2002). No entanto, o sucesso da cultura varia dependendo do tipo de microrganismo, metodologia de coleta e procedimentos laboratoriais (SOL et al., 2002), podendo o agente não ser isolado em mais de $50 \%$ das amostras (TAPONEN et al., 2009). Na tentativa de reduzir o número de amostras falsonegativas, alguns métodos têm sido propostos como o congelamento, pré-incubação e centrifugação das amostras (SCHUKKEN et al., 1989; VILLANUEVA et al., 1991; DINSMORE et al., 1992; ZECCONI et al., 1997; SOL et al., 2002).

Vários estudos avaliaram o efeito de distintos métodos sob o isolamento de patógenos causadores de mastite em bovinos (SCHUKKEN et al., 1989; VILLANUEVA et al., 1991; DINSMORE et al., 1992; COSTA et al., 1996; ZECCONI et al., 1997; SOL et al., 2002) entretanto, os estudos em pequenos ruminantes são escassos (McDOUGALL, 2000; SÁNCHEZ et al., 2003), especialmente em ovinos (CLEMENTS; TAYLOR; FITZPATRICK, 2003). Assim, o presente estudo teve como objetivo avaliar o efeito do congelamento e da incubação do leite de ovinos sobre o isolamento bacteriano.

No presente estudo foram analisadas 45 amostras de leite provenientes de ovelhas da raça Santa Inês. As amostras de leite coletadas assepticamente foram divididas em três alíquotas de acordo com o tratamento as quais foram submetidas. $\mathrm{O}$ primeiro tratamento (T1) consistiu na cultura bacteriológica sendo uma alíquota de $10 \mu \mathrm{L}$ de leite estriada em ágar-sangue de carneiro (5\%) com incubação a $37{ }^{\circ} \mathrm{C}$ por 72 horas e a leitura realizada a cada 24 horas, como recomendado por Oliver et al. (2004). Simultaneamente, a segunda alíquota foi incubada por 18 horas a $37{ }^{\circ} \mathrm{C}(\mathrm{T} 2)$, e a terceira alíquota estocada a $-20{ }^{\circ} \mathrm{C}$ em freezer comercial por 24 horas (T3). Após os períodos estabelecidos para os $\mathrm{T} 2$ e T3, as amostras foram submetidas à cultura bacteriológica, conforme descrito previamente.

A identificação bacteriana foi determinada pelas 
características das colônias podendo ser brancas acinzentadas e amarelas com e quanto a presença e o tipo de hemólise. Posteriormente, duas colônias de cada amostra de leite, semelhantes entre si, foram selecionadas para a realização da coloração de Gram, prova da catalase e coagulase em plasma de coelho (OLIVER et al., 2004). A associação entre as variáveis foi avaliada pelo teste Qui-quadrado de Pearson, e o teste de hipóteses foi conduzido pelo teste de McNemar para amostras pareadas com nível de significância de 5\% utilizando o programa Dag Stat (Diagnostic and Agreement Statistics) (MACKINNON, 2000).

Todas as culturas isoladas foram identificadas como ECN. A porcentagem de amostras positivas ao exame bacteriológico foi de 31,1\% $(n=14), 48,9 \%$ $(n=22)$ e $40,0 \%(n=18)$ para as alíquotas submetidas ao T1, T2 e T3, respectivamente. Desta forma, das 45 amostras analisadas, $11(24,4 \%)$ amostras foram positivas no T1 e T2, $20(44,4 \%)$ amostras foram negativas em ambos os tratamentos, $11(24,4 \%)$ amostras foram positivas no T2 e negativas no T1, 3 $(6,7 \%)$ amostras foram positivas no $\mathrm{T} 1$ e negativas no T2. Ainda do total de amostras avaliadas, 13 $(28,8 \%)$ amostras foram positivas no T1 e T3, 26 $(57,8 \%)$ amostras foram negativas em ambos os tratamentos, $5(11,1 \%)$ amostras foram negativas T1 padrão e positivas no T3, $1(2,2 \%)$ amostra foi positiva no T1 e negativa no T3. Assim, observouse aumento significativo do isolamento de ECN no leite de ovelhas apenas após o T2 (Qui-Quadrado $=4,57)(\mathrm{P}=0,033)$, não ocorrendo com o T3 (Quiquadrado $=2,67)(\mathrm{P}=0,10)$ comparado com o T1. No entanto, salienta-se que $8,9 \%(\mathrm{n}=4)$ das amostras submetidas ao T2 apresentaram desenvolvimento de Bacillus spp.

No presente estudo não foi observado aumento significativo do número de amostras positivas para ECN após congelamento, como relatado por outros autores em amostras de leite de bovinos (DINSMORE et al., 1992; MURDOUGH; DEITZ; PANKEY, 1996) e de caprinos (McDOUGALL, 2000). Além disso, Clements, Taylor e Fitzpatrick
(2003), ao analisarem amostras de leite de ovinos, sugeriram que o exame laboratorial nesta espécie pode ser realizado com leite fresco, pois o aumento do isolamento bacteriano após o congelamento só foi observado em pequeno número de amostras. No entanto, outros estudos apontaram aumento no isolamento dos agentes patogênicos nas amostras de leite proveniente de bovinos (SCHUKKEN et al., 1989; COSTA et al., 1996) e caprinos (SÁNCHEZ et al., 2003) após congelamento, que foi associado à localização intracelular de algumas espécies de estafilococos em amostras de leite fresco, como demonstrado para o Staphylococcus epidermitis e $S$. aureus (SCHUKKEN et al., 1989).

Dinsmore et al. (1992), Costa et al. (1996) e Langoni et al. (2009), em amostras de leite bovino, demonstraram maior recuperação de patógenos intramamários após a incubação quando comparado com o congelamento e a cultura bacteriológica padrão, como observado no presente estudo. A multiplicação bacteriana devido às condições favoráveis de desenvolvimento pode explicar este fato (COSTA et al., 1996). Entretanto, a incubação permitiu o desenvolvimento de bactérias normalmente presentes na microbiota dos ductos dos tetos em ovelhas sadias, como o Bacillus spp. (FRAGKOU et al., 2007), como encontrado por Dinsmore et al. (1992), Sol et al. (2002) e Langoni et al. (2009).

A incubação das amostras de leite de ovinos, diferentemente do congelamento, pode ser recomendada como passo a ser incorporado na análise bacteriológica para reduzir a ocorrência de resultados falso-negativos na cultura bacteriológica, aumentando a confiabilidade do diagnóstico da mastite ovina. Ainda determinaria na otimização dos recursos laboratoriais e redução de custos pra os proprietários.

\section{Agradecimentos}

À Fundação de Amparo à Pesquisa do Estado de São Paulo (FAPESP) pelo apoio financeiro ao 
projeto de sanidade da glândula mamária ovina.

\section{Referências}

BERGONIER, D.; CRÉMOUX, R.; RUPP, R.; LAGRIFFOUL, G.; BERTHELOT, X. Mastitis of dairy small ruminants. Veterinary Research, Les Ulis Cedex, v. 34, n. 5, p. 689-716, 2003.

CLEMENTS, A. C. A.; TAYLOR, D. J.; FITZPATRICK, J. L. Evaluation of diagnostic procedures from subclinical mastitis in meat-producing sheep. Journal Dairy Research, Ayr, v. 70, n. 2, p. 139-148, 2003.

COSTA, E. O.; MELVILle, P. A.; RIBEIIRO, A. R.; PARDO, R. B.; WHITE, C. R. Métodos para diagnóstico microbiológico de mastite clínica bovina. Arquivo Brasileiro de Medicina Veterinária e Zootecnia, Belo Horizonte, v. 49, n. 2, p. 159-167, 1996.

DELLA LIBERA, A. M. M. P.; BLAGITZ, M. G.; SOUZA, F. N.; BATISTA, C. F.; AZEDO, M. R.; NENITES, N. R.; MELVILLE, P. A.; GOMES, V. Antimicrobial susceptibility of coagulase-negative staphylococci isolated from meat-producing ewes with mastitis. Arquivo Brasileiro de Medicina Veterinária e Zootecnia, Belo Horizonte, v. 62, n. 6, p. 1499-1502, 2010.

DINSMORE, R. P.; ENGLISH, P. B.; GONZALEZ, R. N.; SEARS, P. M. Use of augmented cultural techniques in the diagnosis of the bacterial cause of clinical bovine mastitis. Journal of Dairy Science, Champaign, v. 75, n. 10, p. 2706-2712, 1992.

FRAGKOU, I. A.; MAVROGIANNI, V. S.; CRIPPS, P. J.; GOUCOULIS, D. A.; FTHENAKIS, G. C. The bacterial flora in the teat duct of ewes can protect against and can cause mastitis. Veterinary Research, Les Ulis Cedex, v. 38, n. 4, p. 525-545, 2007.

GODDEN, S. M.; JANSEN, J. T.; LESLIE, K. E.; SMART, N. L.; KELTON, D. F. The effect of sampling time and sample handling on the detection of Staphylococcus aureus in milk from quarters with subclinical mastitis. Canadian Veterinary Journal, Ottawa, v. 43, n. 1, p. 3842, 2002.

GONZALO, C.; ARIZNABARRETA, A.; CARRIEDO, J. A. Mammary pathogens and their relationship to somatic cell count and milk yield losses in dairy ewes. Journal of Dairy Science, Champaign, v. 85, n.6, p. 1460-1467, 2002.

LANGONI, H.; LAURINO, F.; FACCIOLI, P. Y.; SILVA, A. V.; MENOZZI, B. D. Cultivo microbiológico e sensibilidade no isolamento de patógenos nas mastites bovinas. Veterinária e Zootecnia, Botucatu, v. 16, n. 4, p. 708-715, 2009.

LEITNER, G.; CHAFFER, M.; ZAMIR, S.; MOR, T.; GLICKMAN, A.; WINKLER, M.; WEISBLIT, L.; SARAN, A. Udder disease etiology, milk somatic cell counts and NAGase activity in Israeli Assaf sheep throughout lactation. Small Ruminant Research, Amsterdan, v. 39, n. 2, p. 107-112, 2001.

MACKINNON, A. A spreadsheet for the calculation of comprehensive statitiscs for the assessment of diagnostic tests and inter-rater agreement. Computer in Biology and Medicine, Philadelphia, v. 30, n. 3, p. 127-134, 2000.

McDOUGALL, S. Recovery of bacteria from goat's milk following freezing and the prevalence of bacteria infection in milk from goats with an elevated somatic cell count. New Zealand Veterinary Journal, Palmerston North, v. 48, n. 1, p. 27-29, 2000.

MURDOUGH, P. A.; DEITZ, K. E.; PANKEY, J. W. Effects of freezing on the viability of nine pathogens from quarters with subclinical mastitis. Journal of Dairy Science, Champaign, v. 79, n.2, p. 334-336, 1996.

OLIVER, S. P.; LEWIS, M. J.; GILLESPIE, B. E.; DOWLEN, H. H.; JAENICKE, E. C.; ROBERTS, R. K. Microbiological procedures for the diagnosis of bovine udder infection and determination of milk quality. $4^{\text {th }} \mathrm{ed}$. Verona, WI: National Mastitis Council, 2004. 47 p.

PENGOV, A. The role of coagulase-negative staphylococcus spp. and associated somatic cell counts in the ovine mammary gland. Journal of Dairy Science, Champaign, v. 84, n.3, p. 572-574, 2001.

SÁNCHEZ, A.; CONTRERAS, A.; JIMÉNEZ, J.; LUENGO, C.; CORRLAES, J. C.; FERNÁNDEZ, C. Effect of freezing goat milk samples on recovery of intramammary bacterial pathogens. Veterinary Microbiology, Geneva, v. 94, n. 1, p. 71-77, 2003.

SCHUKKEN, Y. H.; SMIT, J. A. H.; GROMMERS, F. J.; VANDEGEER, D.; BRAND, A. Effect of freezing on bacteriologic culturing of mastitis milk samples. Journal of Dairy Science, Champaign, v. 72, n.7, p. 1900-1906, 1989.

SOL, J.; SAMPIMON, O. C.; HARTMAN, E.; BARKEMA, H. W. Effect of preculture freezing and incubation on bacteriological isolation from subclinical mastitis samples. Veterinary Microbiology, Genova, v. 85, n. 3, p. 241-249, 2002.

TAPONEN, S.; SALMIKIVI, L.; SIMOJOKI, H.; KOSKINEN, M. T.; PŸORÄLLÄ, S. Real-time polymerase chain reaction-based identification of bacteria in milk samples from bovine clinical mastitis with no growth in conventional culture. Journal of Dairy 
Science, Champaign, v. 92, n. 6, p. 2610-2617, 2009.

VERÍSSIMO, C. J.; ZAFALON, L. F.; OSTUK, I. P.; NASSAR, A. F. C. Prejuízos causados pela mastite em ovelhas Santa Inês. Arquivos do Instituto Biológico, São Paulo, v. 77, n. 4, p. 583-591, 2010.

VILLANUEVA, M. R.; TYLER, J. W.; THURMOND, M. C. Recovery of Streptococcus agalactiae and Staphylococcus aureus from fresh and frozen bovine milk. Journal of American Veterinary Medical Association, Washington, v. 198, n. 8, p. 1398-1400, 1991.

ZECCONI, A.; PICCININI, R.; ZEPPONI, A.; RUFFO, G. Recovery of Staphylococcus aureus from centrifuged quarter milk samples. Journal of Dairy Science, Champaign, v. 80, n. 11, p. 3058-3063, 1997. 
